\title{
Altered Adenylyl Cyclase Activities and G-Protein Abnormalities in Portal Hypertensive Rabbits
}

Paul A. Cahill, Yuping Wu, and James V. Sitzmann

The Johns Hopkins Medical Institutions, Department of Surgery, Baltimore, Maryland 21287-4665

\begin{abstract}
Portal hypertension (PHT) is characterized by splanchnic hyperemia due to a reduction in mesenteric vascular resistance. We hypothesized that alterations in the activity of a guaninenucleotide regulatory protein (G-protein) might be partially responsible for the marked circulatory disturbances observed in PHT. We, therefore, determined alterations in adenylyl cyclase/cAMP system in prehepatic portal hypertensive rabbits and correlated these changes to the activity of a G-protein. Basal and G-protein-stimulated adenylyl cyclase activities were lower in the PHT superior mesenteric artery (22-26\%) and thoracic aorta (31-46\%) membranes, but higher (178$321 \%$ ) in portal vein. The functional activity of Gi $\alpha$ proteins (pertussis toxin-catalyzed ADP-dependent ribosylation) increased in the PHT superior mesenteric artery and thoracic aorta, but decreased in portal vein. Immunodetection revealed an increase in the Gi $\alpha$ protein subunits (Gi $\alpha 1$ / Gi $\alpha 2$ and Gi $\alpha 3$ / Go $\alpha$ ) in PHT thoracic aorta, without any change in Gs $\alpha$ proteins; and a decrease in the amount of Gi $\alpha$ proteins in PHT portal vein. There was no change in the amount of Gs $\alpha / \mathrm{Gi} \alpha$ in the PHT superior mesenteric artery. We conclude the hemodynamic alterations of PHT are associated with intrinsic alterations in G-protein-enzyme effector systems. These alterations are vessel specific and suggest a possible unique global derangement underlying the vasculopathy of PHT. (J. Clin. Invest. 1994. 93:2691-2700.) Key words: G-protein • adenylyl cyclase • portal hypertension • portal blood flow $\bullet$ mesenteric blood flow
\end{abstract}

\section{Introduction}

Chronic portal hypertension (PHT) ${ }^{1}$ results in both increased portal pressure and reduced splanchnic vascular resistance, leading to marked splanchnic hyperemia (1). Similar changes have been reported in several animal models of PHT (1). Prehepatic PHT due to portal venous obstruction is associated with a fall in portal venous collateral resistance as the portal-

\footnotetext{
Address correspondence to Dr. Paul A. Cahill, The Johns Hopkins Hospital, Department of Surgery, Blalock 665, 600 North Wolfe Street, Baltimore, MD 21287-4665.

Received for publication 7 June 1993 and in revised form 24 January 1994

1. Abbreviations used in this paper: $\mathrm{AC}$, adenylyl cyclase; $\mathrm{Gpp}(\mathrm{NH}) \mathrm{p}$ guanyl-5'- $\gamma$-(6-imino)-diphosphate; NL, animals operated on the day of the experiment; PGI, prostacyclin; PHT, portal hypertension; PV portal vein; SMA, superior mesenteric artery; TA, thoracic aorta; TBS, Tris-buffered saline.
}

J. Clin. Invest.

(c) The American Society for Clinical Investigation, Inc.

$0021-9738 / 94 / 06 / 2691 / 10 \quad \$ 2.00$

Volume 93, June 1994, 2691-2700 collateral shunt develops (2-4). Several studies indicate that the increase in splanchnic arterial blood flow could maintain elevations in portal pressure despite the development of portosystemic collaterals, which shunt up to $90 \%$ of the total portal blood flow (2-4). This increase in portal inflow is associated with a reduction in both peripheral vascular resistance and systemic arterial pressure, resulting in an increase in cardiac output (2). In addition, there is a decreased splanchnic and systemic vascular responsiveness to vasoconstrictor stimuli (3-5). However, both the mechanism of the hemodynamic changes and its relationship to PHT is not well understood.

The etiology of the increased mesenteric blood flow includes a decreased responsiveness to and/or production of endogenous vasoconstrictors $(5,6)$ or an excess of vasodilatory substances $(3,4,7,8)$. The suggested major vasoactive substances in PHT are angiotensin-II, vasopressin, $\alpha$-adrenergics, $\beta$-adrenergics, glucagon, nitric oxide, and prostacyclin ( $\left.\mathrm{PGI}_{2}\right)$ $(3,7,9,10)$. PHT is associated with an increase in serum prostacyclin, nitric oxide, catecholamine, and glucagon concentrations $(3,4,7,9-11)$. Chronically elevated levels of these hormones may lead to an impairment of both neural $(\alpha / \beta$ adrenergic) and humoral (angiotensin-II and vasopressin) control of splanchnic vascular resistance. Recently, it has been suggested that the pressor hyporesponsiveness to norepinephrine, vasopressin, and angiotensin-II in the superior mesenteric artery and thoracic aorta of PHT rats may be partially related to the ability of exogenously applied dilators (e.g., $\mathrm{PGI}_{2}$, glucagon, and nitric oxide) to interfere with the actions of exogenously applied vasoconstrictors (1). These reports have led many investigators to suggest that loss of vascular responsiveness to these vasoconstrictive hormones in the portal-mesenteric vein and superior mesenteric artery may contribute both to the increase in portal pressure and the intestinal vasodilation of PHT $(3,4,6,11)$. In alcoholic cirrhosis, portal venous pressure correlates significantly with the activity of the sympathetic nervous system (12). This correlation implies a direct regulatory influence of the sympathetic nervous system on splanchnic hemodynamics and portal pressure.

Guanine-nucleotide regulatory proteins (G-proteins) are key components in cellular signaling processes. G-proteins are a family of cell membrane proteins that link cell surface receptors to intracellular second messenger systems; e.g., adenylyl cyclase (AC) and phospholipase C. Generation of cAMP by $\mathrm{AC}$ is under dual control from receptor-coupled $\mathrm{G}$ proteins, namely Gs proteins, which serve to couple stimulatory receptors to $\mathrm{AC}$, and $\mathrm{Gi}$ proteins, which serve to couple inhibitory receptors to AC (13). Previous studies have reported a downregulation of $\beta$-adrenoreceptors in cirrhotic patients (14). Moreover, cAMP responsiveness to $\beta$-adrenoreceptor stimulation is diminished in lymphocytes of cirrhotic patients (14). This may indicate sympathetic abnormalities in PHT and could reflect a down-regulation of adrenergic receptors. This is suggested by work showing resistance to the vasoconstrictive 
effect of exogenous norepinephrine in the intestinal and peripheral vasculature of experimental animals (11) and in man (12). Moreover, the catecholamine-induced relaxation (after $\alpha$-adrenoceptor blockade) of portal and mesenteric veins from portal hypertensive rats is decreased in PHT $(15,16,17)$. Some investigators suggest that in the prehepatic PHT rat model the most important functional vasoconstrictor defect is loss in adrenergic vascular tone within the intestinal microcirculation (11). Diminished splanchnic vascular responsiveness to norepinephrine may involve altered function of the receptor and/or postreceptor processes that ultimately result in contraction.

Therefore, the aim of the present study was to investigate the responsiveness of PHT animals to sympathetic stimulation by determination of cAMP levels since it has been suggested that the AC/cAMP system is one of the major biochemical mechanisms that participates in the regulation of arterial tone and reactivity (18). Furthermore, we have determined the stimulatory effects of guanine nucleotides and the diterpene derivative, forskolin, on AC activity and correlated these changes to alterations in the amount and functional activity of guanine nucleotide regulatory proteins $(\mathrm{Gs} / \mathrm{Gi}$ ) using both pertussis toxin- and cholera toxin-sensitive ribosylation of Gi $\alpha$ and Gs/ substrates and specific antibodies for Gs $\alpha$ and $\mathrm{Gi} \alpha$.

\section{Methods}

Materials. ATP, GTP, cAMP, creatinine phosphate, creatine phosphokinase, guanyl-5'- $\gamma$ - $(\beta$-imino $)$-diphosphate, $[\mathrm{Gpp}(\mathrm{NH}) \mathrm{p}]$, pertussis toxin, and forskolin were purchased from Sigma Chemical Co. (St. Louis, MO). [ $\alpha^{32} \mathrm{P}$ ]ATP ( $\left.800 \mathrm{Ci} / \mathrm{mmol}\right)$, [adenylate- ${ }^{32} \mathrm{P}$ ]NAD ( 800 $\mathrm{Ci} / \mathrm{mmol}$ ), cyclic $\left[{ }^{3} \mathrm{H}\right] \mathrm{AMP}(30 \mathrm{Ci} / \mathrm{mmol})$, and ${ }^{125} \mathrm{I}$-rProtein $\mathrm{A}$ $(2,000 \mathrm{Ci} / \mathrm{mmol})$ were purchased from New England Nuclear (Boston, MA). Antisera against Gs $\alpha$ (RM/1), Gi $\alpha 1 / \mathrm{Gi} \alpha 2$ (AS/7), and $\mathrm{Gi} \alpha 3 / \mathrm{Go} \alpha(\mathrm{EC} / 2)$ were purchased from New England Nuclear. Nitrocellulose membranes (HYBOND-C) were obtained from Amersham (Arlington Heights, IL). All other chemicals were of the highest purity commercially available.

Animals. Adult male New Zealand white rabbits (2.7-3.3 kg) were used for all studies. Rabbits were housed in a controlled environment and allowed free access to a moderate sodium diet (Purina Rabbit Chow, sodium $0.33 \%$, Ralston Purina Co., St. Louis, MO) until the time of study. All studies were approved by the Johns Hopkins University Animal Care and Use Committee and adhered to American Association for Laboratory Animal Care federal guidelines for the humane care and treatment of animals. Prehepatic PHT was produced by partial portal vein ligation, as described previously (5). Briefly, a laparotomy was performed under ketamine $\mathrm{HCl}(25 \mathrm{mg} / \mathrm{kg}$ body wt i.v.) and $1 \%$ xylocaine local anesthesia. Under aseptic conditions the portal vein was isolated and a ligature was placed around the portal vein distal to the confluence of the right and left branches. A blunt 18-gauge needle was placed alongside the portal vein, the ligature was tightened around the needle and vein, and the needle was removed, producing a standard, calibrated stenosis. The abdomen was closed and the animal allowed to recover for $3 \mathrm{wk}$. Control animals were acclimated for $1 \mathrm{wk}$ before the study.

Hemodynamic studies. Animals had their hemodynamics characterized, as previously described (5). Briefly, animals were anesthetized with ketamine $\mathrm{HCl}$ and $1 \%$ xylocaine local anesthetic. Laparotomy and femoral cutdown was performed. Both artery and veins were cannulated, and aortic and central venous pressures were measured by a strain gauge transducer. The portal venous pressure was measured by a manometer connected to the catheter, which was cannulated from the branch of the mesenteric vein and advanced into the portal vein. An ultrasonic Doppler flow probe (Transonic Corp., Ithaca, NY) was placed around the superior mesenteric artery. The hemodynamics of this model of PHT have been characterized extensively (3-5). There were no detectable differences observed between the hemodynamics of animals operated on the day of the experiment (NL), and the animals operated on 3 wk earlier (sham) (data not shown).

Preparation of membranes. Animals were killed with intravenous sodium phenobarbital. The superior mesenteric artery (SMA) was dissected to its tertiary branches, transected from the aorta, harvested, and placed in ice-cold buffer containing $10 \mathrm{mM}$ Tris $\mathrm{HCl}$ and $1 \mathrm{mM}$ EDTA ( $\mathrm{pH} 7.5$ ). The portal vein proximal to the ligature and to the tertiary branches of the superior mesenteric vein, and the small intestine were harvested and placed in buffer. Thoracic aorta and adrenals were also removed and placed in buffer. Adherent fat was removed by sharp dissection. Tissues were minced with a fine scissors and homogenized in a Tissumiser (Tekmar Ultra Turrax; Tekmar, Cincinnati, $\mathrm{OH}$ ) for $10 \mathrm{~s}$ intervals. The homogenates were filtered through pre-wet nylon gauze and concentrated by centrifugation at $1,000 \mathrm{rpm}$ for $10 \mathrm{~min}$ at $4^{\circ} \mathrm{C}$. The supernatants were transferred and centrifuged at $30,000 \mathrm{~g}$ for $30 \mathrm{~min}$ at $4^{\circ} \mathrm{C}$. The supernatants were discarded, and the pellets were resuspended in $10 \mathrm{mM}$ Tris $\mathrm{HCl}$ containing $1 \mathrm{mM}$ EDTA ( $\mathrm{pH} 7.5$ ), and washed at $30,000 \mathrm{~g}$ for $30 \mathrm{~min}$ at $4^{\circ} \mathrm{C}$. The resulting pellet was resuspended in $50 \mathrm{mM}$ Tris $\mathrm{HCl}$ ( $\mathrm{pH} 7.4)$ containing $1 \mathrm{mM}$ EDTA and stored at $70^{\circ} \mathrm{C}$. Protein was measured by the method of Bradford (19) with BSA as a standard and subsequently used for determination of AC activity, ADP-ribosylation, and immunoblotting.

Adenylyl cyclase activity. AC activity was determined by measuring $\left[{ }^{32} \mathrm{P}\right] \mathrm{cAMP}$ formation from $\left[\alpha{ }^{32} \mathrm{P}\right]$ ATP $(20)$. The assay medium containing $50 \mathrm{mM}$ Tris $\mathrm{HCl}$, pH 7.5, $0.5 \mathrm{mM}$ MgATP, $\left[\alpha-{ }^{32} \mathrm{P}\right] \mathrm{ATP}$ $\left(\sim 1-1.5 \times 10^{6} \mathrm{cpm}\right.$ ), $4 \mathrm{mM} \mathrm{MgCl} 2,200 \mathrm{mM} \mathrm{NaCl}, 100 \mu \mathrm{M}$ GTP (or otherwise indicated), $10 \mathrm{mM}$ theophylline, and an ATP-regenerating system containing $0.6 \mathrm{mg} / \mathrm{ml}$ creatine phosphokinase and $6.6 \mathrm{mg} / \mathrm{ml}$ phosphocreatinine in final volume of $0.15 \mathrm{ml}$. Incubations were initiated by the addition of membrane preparation to the reaction mixture (SMA: $10-50 \mu \mathrm{g}$, PV: $50-100 \mu \mathrm{g}$, TA: $10-50 \mu \mathrm{g}$, ADR: 50-100 $\mu \mathrm{g}$, which had been equilibrated for $2 \mathrm{~min}$ at $37^{\circ} \mathrm{C}$. The reactions, conducted in triplicate for $15 \mathrm{~min}$ at $37^{\circ} \mathrm{C}$, were terminated by the addition of a $0.1 \mathrm{ml}$ stopping solution containing ice-cold $10 \mathrm{mM}$ Tris $\mathrm{HCl}, \mathrm{pH}$ $7.5,2 \% \mathrm{SDS}, 2 \mathrm{mg} / \mathrm{ml} \mathrm{ATP}$, and $0.5 \mathrm{mg} / \mathrm{ml}$ cAMP. The cAMP formed was separated by sequential chromatography on Dowex and neutral alumina, as previously described (20). Chromatographic yields were $75-85 \%$. Specific activities were expressed as picomoles of cAMP formed per milligram of protein.

Pertussis toxin catalyzed ADP ribosylation. G-protein substrates of pertussis toxin were assayed using pertussis toxin-catalyzed incorporation of $\left[{ }^{32} \mathrm{P}\right] \mathrm{ADP}$-ribose from $\left[{ }^{32} \mathrm{P}\right] \mathrm{NAD}$, as previously described (20). Membranes (20-30 $\mu \mathrm{g}$ ) were resuspended in $100 \mu \mathrm{l}$ of $100 \mathrm{mM}$ Tris $\mathrm{HCl}$, pH 8 , containing $5 \mathrm{mM}$ DTT, $10 \mathrm{mM}$ thymidine, $6 \mathrm{mM}$ $\mathrm{MgCl}_{2}, 2 \mathrm{mM}$ GTP, $2.5 \mathrm{mM} \mathrm{ATP}$, and $10 \mathrm{M}\left[{ }^{32} \mathrm{P}\right] \mathrm{NAD}$. Pertussis toxin $(100 \mu \mathrm{g} / \mathrm{ml})$ was activated by prior incubation in $50 \mathrm{mM}$ Hepes, $\mathrm{pH} 8$, containing $20 \mathrm{mM}$ DTT, $0.125 \%$ SDS, and $0.1 \mathrm{mg} / \mathrm{ml} \mathrm{BSA}$ for $30 \mathrm{~min}$ at room temperature. After addition of activated pertussis toxin $(20 \mu \mathrm{g} / \mathrm{ml})$, the membrane preparations were incubated for $90 \mathrm{~min}$ at $30^{\circ} \mathrm{C}$. The ADP-ribosylation reactions were stopped by centrifugation at $15,000 \mathrm{~g}$ for $3 \mathrm{~min}$, and the pellet was resuspended in SDS-sample buffer containing $62.5 \mathrm{mM}$ Tris $\mathrm{HCl}, \mathrm{pH} 6.8,2 \%$ SDS, $10 \%$ glycerol, and $5 \% \beta$-mercaptoethanol. The samples were boiled for $10 \mathrm{~min}$ before being resolved on a $10 \%$ SDS polyacrylamide gel, as previously described (21). Gels were dried on cellophane and exposed to Kodak XAR-5 film with an intensifying screen at $70^{\circ} \mathrm{C}$ for 3-4 d. Equal protein loading was confirmed by Coomassie blue-staining of protein in each lane of the same gel. The signal intensity (integral volume) of the appropriate bands on the autoradiogram was analyzed using a personal densitometer (Molecular Dynamics, Sunnyvale, CA) using the Imagequant software package (Biosoft, Indianapolis, IN).

Cholera toxin-catalyzed ADP-dependent ribosylation. G-protein substrates of cholera toxin were assayed using cholera toxin-catalyzed incorporation of $\left[{ }^{32} \mathrm{P}\right] \mathrm{ADP}$-ribose from $\left[{ }^{32} \mathrm{P}\right] \mathrm{NAD}$, as previously described (20). Membranes (40-60 $\mu \mathrm{g}$ ) were incubated in $100 \mu \mathrm{l}$ of buffer ( $\mathrm{pH} \mathrm{7}$ ), containing $100 \mathrm{mM}$ potassium phosphate, $2 \mathrm{mM} \mathrm{GTP \text {, }}$ 
$2.5 \mathrm{mM}$ ATP, $20 \mathrm{mM}$ thymidine, $10 \mathrm{U}$ aprotinin, and $10 \mathrm{M}\left[{ }^{32} \mathrm{P}\right] \mathrm{NAD}$ $(800 \mathrm{Ci} / \mathrm{mmol})$. Cholera toxin was activated by incubating in $100 \mathrm{mM}$ DTT for $30 \mathrm{~min}$ at $30^{\circ} \mathrm{C}$. After addition of $5 \mu \mathrm{g}$ of activated cholera toxin, the membrane preparations were incubated for $90 \mathrm{~min}$ at $30^{\circ} \mathrm{C}$. The ADP-ribosylation reactions were stopped by centrifugation and analyzed as outlined for pertussis toxin-catalyzed ADP-ribosylation.

Immunoblotting of G-proteins. Membrane proteins were separated on $10 \%$ SDS-polyacrylamide, as described previously (21). After SDSPAGE, the separated proteins were electrophoretically transferred to nitrocellulose membranes (HYBOND-C; Amersham) using a Transphor electroblotter unit (Hoefer Scientific Instruments, San Francisco, $\mathrm{CA}$ ) at $100 \mathrm{~V}$ for $3 \mathrm{~h}$. After transfer, the membranes were incubated for $3 \mathrm{~h}$ in blocking solution containing $50 \mathrm{mM}$ Tris base ( $\mathrm{pH} 7.6$ ), $4 \mathrm{mM}$ $\mathrm{MgCl}_{2}$, and $14 \mathrm{mM} \mathrm{NaCl}$ Tris-buffered saline (TBS) supplemented with $30 \mathrm{mg} / \mathrm{ml} \mathrm{BSA}, 0.1 \%$ Tween- 20 , and $2 \mathrm{mg} / \mathrm{ml}$ sodium azide. The membranes were washed twice for 5 min each with TBS containing $0.1 \%$ (vol/vol) Tween-20 and 2\% (vol/vol) NP-40. The membranes were incubated with the specific antisera (1:1,000 dilution) in TBS containing $1 \%$ (wt/vol) BSA, $0.05 \%$ (vol/vol) Tween-20, 0.02\% (wt/ $\mathrm{vol}$ ) sodium azide, and $2 \%$ ( vol/ $\mathrm{vol}$ ) NP-40 overnight at room temperature with gentle rocking. After washing the blots twice for $30 \mathrm{~min}$ each in TBS containing $0.4 \%$ (wt $/ \mathrm{vol}$ ) SDS, $4 \%$ ( $\mathrm{vol} / \mathrm{vol}$ ) NP-40, they were incubated with the second antibody solution $\left(0.5 \mu \mathrm{Ci} / \mathrm{ml}^{125} \mathrm{I}-\mathrm{rProtein}\right.$ A) diluted in TBS containing $1 \%(\mathrm{wt} / \mathrm{vol}) \mathrm{BSA}, 0.05 \%$ ( vol $/ \mathrm{vol})$ Tween-20, $0.02 \%(\mathrm{wt} / \mathrm{vol}$ ) sodium azide, and $2 \%(\mathrm{vol} / \mathrm{vol}) \mathrm{NP}-40$ for $2 \mathrm{~h}$ at room temperature with gentle agitation. The blots were finally washed twice for $30 \mathrm{~min}$ in TBS containing $0.4 \%$ (wt/vol) SDS, $4 \%$ ( vol/vol) NP-40 and 5 min each in TBS alone before they were covered in cellophane and exposed to Kodak XAR-5 film with an intensifying screen at $70^{\circ} \mathrm{C}$ for 3-4 d. Equal protein loading was confirmed by Coomassie blue-staining of protein in each lane of the same blot. The signal intensity (integral volume) of the appropriate bands on the autoradiogram was analyzed using a personal densitometer (Molecular Dynamics, Sunnyvale, CA) and the Imagequant software package.

Statistics. The data shown are means \pm SEM. Statistical significance was estimated using the following analyses: unpaired Student's $t$ test for comparison of two groups, ANOVA, followed by a Student's $t$ test for multiple comparisons and a Wilcoxon-signed rank test for the densitometric data. A value of $P<0.05$ was considered significant.

\section{Results}

Hemodynamic studies. $3 \mathrm{wk}$ after partial portal vein ligation, portal venous pressure $\left(P_{\mathrm{PV}}\right)$ was significantly increased from $7.9 \pm 0.7$ to $14.7 \pm 0.8 \mathrm{mmHg}(P<0.05)$. This was associated with a markedly elevated superior mesenteric artery blood flow $\left(Q_{\mathrm{SMA}}\right)(93.6 \pm 6.1$ to $148.2 \pm 8.6 \mathrm{ml} / \mathrm{min}$ per $100 \mathrm{~g}$ intestinal wt) and a marked reduction in the superior mesenteric artery resistance $\left(R_{\mathrm{SMA}}\right)(0.86 \pm 0.06$ to $0.43 \pm 0.04 \mathrm{mmHg}$ per $\mathrm{ml} / \mathrm{min}$ per gram intestinal wt) (Table I).
Table I. Hemodynamic Data from Normal and Portal Hypertensive Animals

\begin{tabular}{lcc}
\hline & $\mathrm{NL}$ & $\mathrm{PHT}$ \\
\hline Ppv, mmHg & $7.9 \pm 0.7$ & $14.7 \pm 0.8^{*}$ \\
$Q_{\text {SMA }}, \mathrm{mmHg}$ per ml/min per gram & & \\
$\quad$ intestinal wt & $93.6 \pm 6.1$ & $148.2 \pm 8.6^{*}$ \\
$R_{\text {SMA }}, \mathrm{ml} / \mathrm{min}$ per gram & & \\
$\quad$ intestinal wt & $0.86 \pm 0.06$ & $0.43 \pm 0.04^{*}$ \\
PSS, \% & $<0.1$ & $76.8 \pm 3.6^{*}$ \\
& & \\
\hline
\end{tabular}

${ }^{*} P<0.05 ; \mathrm{NL}, \mathrm{n}=6$; PHT, $\mathrm{n}=6$. NL, normal; PHT, portal hypertension; $P_{\mathrm{PV}}$, portal venous pressure, $R_{\mathrm{SMA}}$, superior mesenteric artery resistance; $Q_{\text {SMA }}$, superior mesenteric artery blood flow; PSS, portosystemic shunt.

$A C$ activities. AC activities in membranes prepared from each tissue were linear with respect to increasing concentrations of protein $(5-100 \mu \mathrm{g})$. AC activity in superior mesenteric artery membranes increased linearly with respect to time in the presence of $10 \mu \mathrm{M} \mathrm{Gpp}(\mathrm{NH}) \mathrm{p}$ for up to 20 min (data not shown). For this reason, an incubation time of $15 \mathrm{~min}$ was chosen for subsequent experiments.

To determine whether the stimulatory actions of guanine nucleotides on AC activity were altered in PHT, the effects of a nonhydrolyzable guanine nucleotide analogue, $\mathrm{Gpp}(\mathrm{NH}) \mathrm{p}$, fluoride $(\mathrm{NaF})$, and the diterpene derivative, forskolin, were examined in superior mesenteric artery, portal vein, thoracic aorta, and adrenal membranes from NL and PHT animals. As outlined in Table II, in the presence of GTP $(100 \mu \mathrm{M})$, basal $\mathrm{AC}$ activity was decreased in membranes prepared from PHT superior mesenteric artery and thoracic aorta by $21 \pm 0.5$ and $46 \pm 2.5 \%$, respectively, compared with NL. Similarly, the response of $\mathrm{AC}$ activity to $10 \mu \mathrm{M} \mathrm{Gpp}(\mathrm{NH}) \mathrm{p}$ was reduced in both superior mesenteric artery and thoracic aorta membranes in PHT when compared with NL (Table II). In the presence of GTP, the basal level of AC activity was higher in PHT portal vein membranes $(178 \pm 60 \%)$. The ability of $\mathrm{Gpp}(\mathrm{NH}) \mathrm{p}, \mathrm{NaF}$, and forskolin to stimulate AC activity in PHT was significantly enhanced in portal vein membranes when compared with NL animals $(810 \pm 248,371 \pm 90,732 \pm 267 \%$, respectively) (Table II). In contrast, neither $\mathrm{Gpp}(\mathrm{NH}) \mathrm{p}$-, NaF-, nor forskolin-stimulated levels of $\mathrm{AC}$ were significantly altered in adrenal membranes prepared from PHT animals. Further examination of $A C$ activity in the absence of GTP revealed basal and stimu-

Table II. Summary of Postreceptor Adenylyl Cyclase Activity in NL and PHT Rabbits

\begin{tabular}{|c|c|c|c|c|c|c|c|c|}
\hline \multirow[b]{2}{*}{ Condition } & \multicolumn{2}{|c|}{ SMA } & \multicolumn{2}{|c|}{ TA } & \multicolumn{2}{|c|}{ PV } & \multicolumn{2}{|c|}{ ADR } \\
\hline & NL & PHT & NL & PHT & NL & PHT & NL & PHT \\
\hline & \multicolumn{2}{|c|}{ pmol cAMP/min per $m g$} & \multicolumn{2}{|c|}{ pmol $c A M P /$ min per $m g$} & \multicolumn{2}{|c|}{ pmol cAMP/min per $m g$} & \multicolumn{2}{|c|}{ pmol $c A M P /$ min per $m g$} \\
\hline Basal & $341 \pm 13$ & $269 \pm 7$ & $228 \pm 10$ & $84 \pm 12$ & $5 \pm 2$ & $11 \pm 2$ & $26 \pm 5$ & $44 \pm 8$ \\
\hline $\mathrm{Gpp}(\mathrm{NH}) \mathrm{p}, 10 \mu \mathrm{M}$ & $523 \pm 44$ & $389 \pm 21$ & $298 \pm 14$ & $137 \pm 10^{*}$ & $10 \pm 2$ & $75 \pm 23^{*}$ & $41 \pm 10$ & $70 \pm 13$ \\
\hline $\mathrm{NaF}, 10 \mathrm{mM}$ & $1,104 \pm 55$ & $843 \pm 32 *$ & $946 \pm 21$ & $531 \pm 11^{*}$ & $25 \pm 6$ & $92 \pm 23^{*}$ & $499 \pm 61$ & $501 \pm 42$ \\
\hline Forskolin, $100 \mu \mathrm{M}$ & $3,669 \pm 91$ & $2,363 \pm 65^{*}$ & $2,271 \pm 20$ & $889 \pm 10^{*}$ & $23 \pm 4$ & $190 \pm 38^{*}$ & $255 \pm 51$ & $233 \pm 49$ \\
\hline
\end{tabular}

All experiments were performed in the presence of GTP and results are the means \pm SEM of three separate experiments performed in triplicate. The levels of adenylyl cyclase in PHT were statistically significant $\left({ }^{*} P<0.05\right)$ compared with NL, as determined by ANOVA using Student's $t$ test with corrections for multiple comparisons. 
lated AC levels were similarly reduced in particulate fractions of superior mesenteric artery and thoracic aorta in PHT (Fig. 1, $a$ and $b$ ).

To study whether the reduced AC activity in the superior mesenteric artery and thoracic aorta of PHT animals was due to defective G-protein-effector coupling, enzyme activity was studied in the presence of $\mathrm{MnCl}_{2}$. Manganese ions are known to uncouple the catalytic subunit of $\mathrm{AC}$ from guanine nucleotide regulatory sites (22). Thus, under these conditions, the activity of the catalyst can be studied (Fig. 2). In superior mesenteric artery and thoracic aorta membranes from PHT animals, AC activity was significantly lower in the presence of 5 $\mathrm{mM} \mathrm{MnCl}{ }_{2}$ (Fig. 2, $a$ and $b$ ) in the absence or presence of forskolin, indicating the catalytic subunit of $\mathrm{AC}$ may be depressed in PHT superior mesenteric artery and thoracic aorta membranes. In the case of the portal vein membranes prepared from PHT animals, AC activity was elevated in the presence of $5 \mathrm{mM} \mathrm{MnCl}$. Moreover, in the absence/presence of forskolin and $\mathrm{MnCl}_{2}$ there was a significant increase in the AC activity in PHT portal vein (Fig. $2 c$ ). These results imply that basal and stimulated levels of AC activity are impaired in the vasculature of PHT. Moreover, these changes in responsiveness to guanine nucleotide-, NaF-, and forskolin-stimulated cyclase activity are vessel specific and may involve changes in the catalytic subunit of $\mathrm{AC}$.

Pertussis toxin-catalyzed $\left[{ }^{32} P\right] A D P$ dependent ribosylation. One possible explanation for the changes in AC activity in PHT is altered functional activity of guanine nucleotide regulatory proteins ( Gi $\alpha / \mathrm{Gs} \alpha)$. We examined the extent of pertussis toxin-catalyzed ribosylation of G-protein substrates using pertussis toxin-catalyzed incorporation of $\left[{ }^{32} \mathrm{P}\right] \mathrm{ADP}$-ribose from [ $\left.{ }^{32} \mathrm{P}\right]$ NAD. Pertussis toxin catalyzed the incorporation of $\left[{ }^{32} \mathrm{P}\right]-$ ADP-ribose into one major peptide band ( 40,000 mol wt) in normal superior mesenteric artery membranes (Fig. $3 a$ ). The ribosylation increased over a range of $10-100 \mu \mathrm{g}$ of membrane protein and was linear up to $60 \mu \mathrm{g}$ (Fig. $3 \mathrm{~b}$ ). Therefore, a concentration of 20-30 $\mu \mathrm{g}$ of protein was chosen in all subsequent ribosylation experiments.

The amount of $\left[{ }^{32} \mathrm{P}\right]$ ADP-ribose incorporated by pertussis toxin was increased in superior mesenteric artery and thoracic aorta membranes from PHT, compared with NL (Fig. $4 a$ ). Relative to the $40-\mathrm{kD}$ pertussis toxin substrate levels in superior mesenteric artery and thoracic aorta membranes of $10 \mathrm{NL}$ rabbits, the levels in 7 PHT animals were increased by $288 \pm 60$ and $326 \pm 90 \%$, respectively $(P<0.01)$ (Fig. $4 b$ ). No significant labeling was detected in the absence of pertussis toxin (Fig. $4 a$ ). In contrast to the PHT, superior mesenteric artery and thoracic aorta membranes, the amount of $\left[{ }^{32} \mathrm{P}\right]$ ADPribose incorporated by pertussis toxin was significantly reduced $(69 \pm 7 \%, P<0.01)$ in PHT portal vein membranes, compared with NL (Fig. 4, $a$ and $b$ ). There was no significant difference in the labeling of the $40 \mathrm{kD}$ pertussis toxin substrate protein in adrenal membranes prepared from NL and PHT animals, respectively (Fig. 4, $a$ and $b$ ).

Immunoblotting of $G$-proteins. Since pertussis-toxin catalyzes the ribosylation of several G-proteins ( $\mathrm{Gi} \alpha 1, \mathrm{Gi} \alpha 2, \mathrm{Gi} \alpha 3$, and $\mathrm{Go} \alpha$ ), it was of interest to identify the G-proteins that may be altered in PHT. therefore, the amount of immunodetectable G-protein levels were determined using specific antisera against $\mathrm{Go} \alpha, \mathrm{Gs} \alpha$, and different isoforms of $\mathrm{Gi} \alpha$. The specific antibodies used were raised against $\mathrm{Gi} \alpha 1 / \mathrm{Gi} \alpha 2$ (AS/7), $\mathrm{Gi} \alpha 3 / \mathrm{Go} \alpha(\mathrm{EC} / 2)$, and Gs $\alpha(\mathrm{RM} / 1)$. On Western blots prepared from particulate fractions of normal superior mesenteric artery, antiserum against $\mathrm{Gi} \alpha 1 / \mathrm{Gi} \alpha 2(\mathrm{AS} / 7$ ) recognized a major protein band with relative molecular weight of 40,000 (Fig. 3 ). The autoradiographic intensity of antibody binding to this protein band was linearly related to the total membrane protein applied to the gel ( $10-70 \mu \mathrm{g})$ on Western blots probed with AS/ 7 antiserum (Fig. 3). Similar results were observed for thoracic aorta membranes using the AS/7 antibody (data not shown). Therefore, the antisera could be used to determine the relative concentrations of immunodetectable peptides in particulate fractions from NL and PHT superior mesenteric artery, portal vein, and adrenal and thoracic aorta membranes. As shown in Fig. $5 a$, relative levels of the peptides detected by antiserum AS/7 (Gi $\alpha 1 / \mathrm{Gi} \alpha 2)$ were significantly different in PHT thoracic aorta and portal vein membranes. In particular, the relative amounts of $\mathrm{Gi} \alpha 1 / \mathrm{Gi} \alpha 2$ were significantly increased by $288 \pm 80 \%, P<0.01$ in PHT thoracic aorta membranes and decreased by $59 \pm 17 \%, P<0.01$ in PHT portal vein
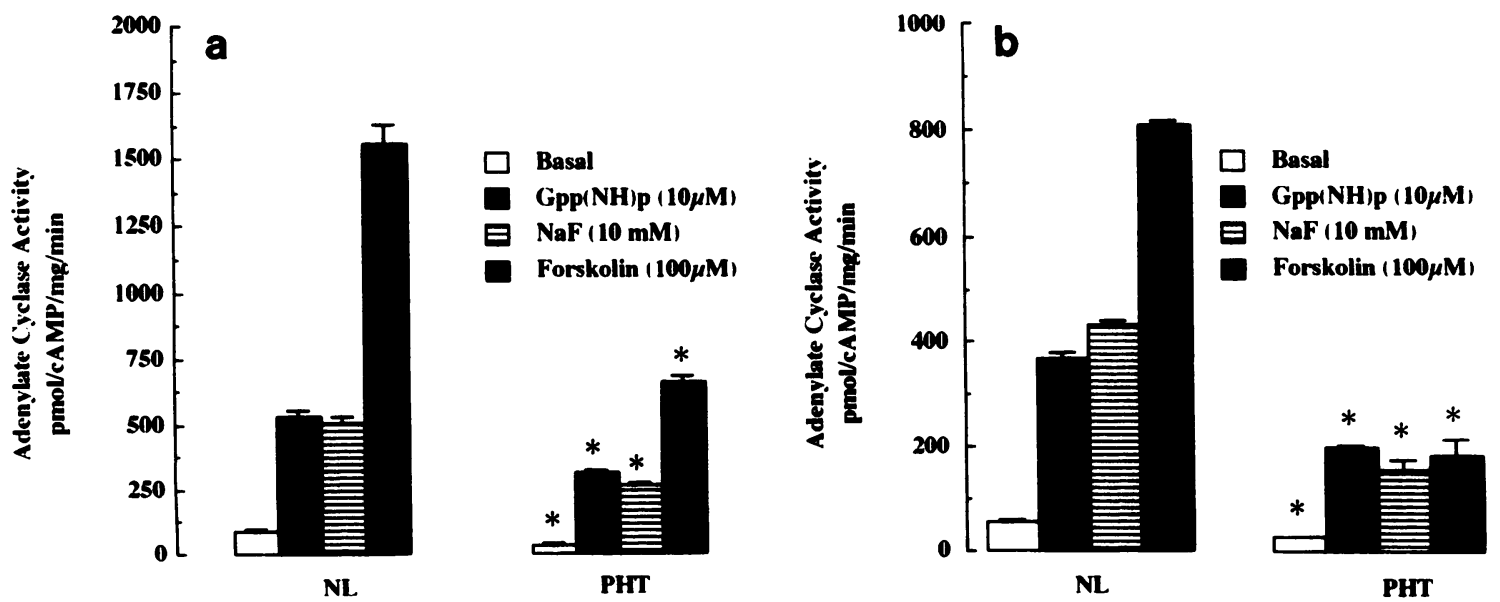

Figure 1. Adenylate cyclase activity in the superior mesenteric artery $(a)$ and thoracic aorta $(b)$ of normal (NL) and portal hypertensive (PHT) rabbits. Basal and stimulated adenylyl cyclase activities [ $\mathrm{Gpp}(\mathrm{NH}) \mathrm{p}, \mathrm{NaF}$, and forskolin)] were measured in the absence of GTP as outlined in Methods. Results are expressed as picomoles of $\mathrm{cAMP} / \mathrm{mg}$ per min and are the means \pm SEM of 6 determinations. The stimulated levels of adenylyl cyclase in PHT were statistically significant $\left({ }^{*} P<0.05\right)$, as determined by ANOVA. 

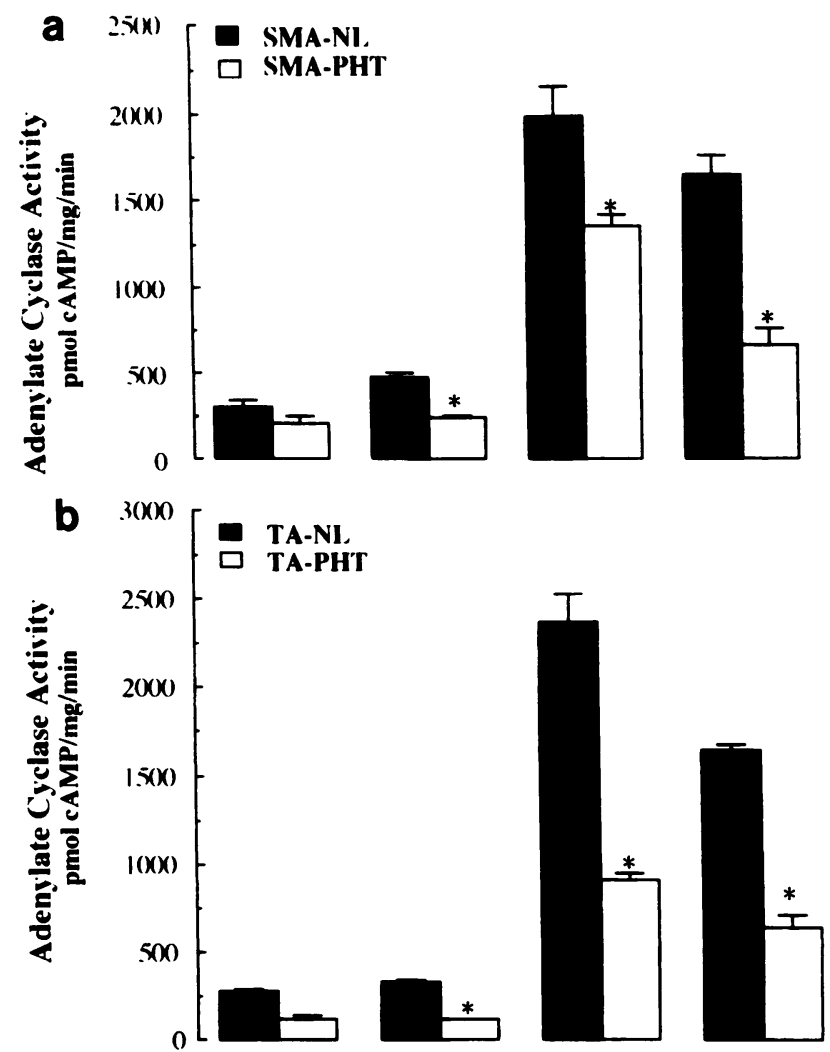

\section{C}

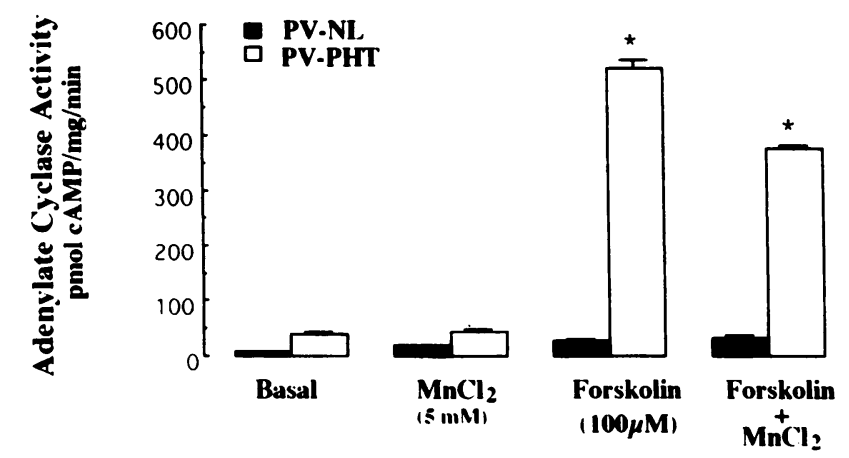

Figure 2. The effect of manganese ions on adenylyl cyclase activity in the superior mesenteric artery $(a)$, thoracic aorta $(b)$, and portal vein (c) of normal (NL) and portal hypertensive (PHT) rabbits. Basal and stimulated adenylyl cyclase activity after stimulation with forskolin $(100 \mu \mathrm{M})$ in the absence or presence of $5 \mathrm{mM} \mathrm{MnCl}_{2}$. Results are expressed as picomoles of cAMP/milligram per minute and are the means \pm SEM of 3-6 determinations. The levels of adenylyl cyclase in PHT were statistically significant $\left({ }^{*} P<0.05\right)$ as determined by unpaired Student's $t$ test.

membranes (Fig. 5, b). The amount of immunodetectable Gi $\alpha 1 / \mathrm{Gi} \alpha 2$ in superior mesenteric artery and adrenal membranes was not significantly altered in NL versus PHT animals (Fig. $5 b$ ).

Using the antiserum against $\mathrm{Gi} \alpha 3 / \mathrm{Go} \alpha(\mathrm{EC} / 2)$, the amount of immunodetectable Gi $\alpha 3 /$ Go $\alpha$ was significantly increased in PHT thoracic aorta membranes (1.58 \pm 0.13 -fold, $P$ $<0.01$ increase compared with $\mathrm{NL}$ ), and significantly reduced in the PHT portal vein fractions by $66 \pm 19 \%(P<0.01)$ (Fig. 6 , $a$ and $b)$. There was no significant difference in the amount of immunodetectable Gi $\alpha 3$ / Go $\alpha$ peptides present on either supe- rior mesenteric artery or adrenal membranes prepared from PHT compared with NL animals (Fig. 6, $a$ and $b$ ).

To substantiate that these peptides were $\mathrm{Gi} \alpha 1 / \mathrm{Gi} \alpha 2$ species, we assessed whether they co-migrated with the pertussis toxin substrate in particulate fractions of NL artery. Particulate fractions of normal superior mesenteric artery were ADP-ribosylated with $\left[{ }^{32} \mathrm{P}\right] \mathrm{NAD}$. Parallel samples were not treated with $\left[{ }^{32} \mathrm{P}\right]$ NAD. The reaction products were resolved by SDS/ PAGE. Electroblotting of the sample lanes that had not been ADP-ribosylated and subsequent probing with AS/7 antiserum demonstrated that the ${ }^{32} \mathrm{P}$ labeled protein co-migrated with the relative molecular mass of $40 \mathrm{kD}$ peptide recognized by the AS/ 7 antiserum (data not shown). Similar results were observed when these experiments were repeated with antibody EC/2 (data not shown). With the electrophoresis conditions adopted in these experiments, ADP-ribosylation did not substantially alter the electrophoretic migration of the Gi $\alpha$ proteins. These results support the conclusion that the 40,000-mol wt peptide is a $\mathrm{Gi} \alpha$ protein.

Since changes in AC activity could result from altered levels of functional Gs $\alpha$ activity, we investigated the amount of Gs $\alpha$ in PHT membranes. Using specific antibodies against Gs $\alpha$ $(\mathrm{RM} / 1)$, we determined the levels of Gs $\alpha$ proteins in membranes from NL and PHT animals. Fig. 7, $a$ and $b$, shows that the antiserum RM/ 1 clearly detected 42,000 - and $44 \mathrm{kD}$ forms of the stimulatory Gs $\alpha$ in NL and PHT particulate fractions from superior mesenteric artery, portal vein, thoracic aorta, and ADRs, respectively. The autoradiographic intensity of antibody binding to these protein bands was linearly related to the total membrane protein applied to the gel (10-70 $\mu \mathrm{g})$ on Western blots probed with $\mathrm{RM} / 1$ antiserum (data not shown). However, there was no significant change from NL in the amount of immunodetectable Gs $\alpha$ present in PHT superior mesenteric artery, thoracic aorta, and adrenal membranes (Fig. 7). In contrast, there was a significant reduction in the labeling of $\mathrm{Gs} \alpha$ in portal vein membranes in PHT $(21 \pm 7 \%, P$ $<0.05)$. To further corroborate this finding, we determined cholera toxin-dependent ADP-ribosylation of regulatory protein Gs $\alpha$ in superior mesenteric artery, portal vein, and thoracic aorta membranes from NL and PHT animals. The ribosylation assay was linear over a range of $10-100 \mu \mathrm{g}$ of membrane protein (data not shown). Cholera toxin in the presence of $\left[{ }^{32} \mathrm{P}\right]$ NAD catalyzed the ADP-ribosylation of two protein bands of $42-$ and $44 \mathrm{kD}$ in both NL and PHT animals. Moreover, the cholera toxin substrate co-migrated with the 42- and $44 \mathrm{kD}$ peptides detected using the specific antisera (RM/1) (data not shown). Labeling of either band was not significantly different in PHT superior mesenteric artery and thoracic aorta membranes from NL (Fig. 8, $a$ and $b$ ). In contrast, there was a significant reduction in the labeling of the cholera toxin substrates in PHT portal vein membranes, compared with NL membranes. These results suggest that the amount and functional activity of Gs $\alpha$ is not altered in PHT superior mesenteric artery and thoracic aorta, but is reduced in the portal vein of PHT rabbits.

\section{Discussion}

The current studies define for the first time altered expression of inhibitory guanine nucleotide regulatory proteins (G-proteins) in the vasculature of PHT animals. The response to both guanine nucleotide and catalytic subunit stimulation of $\mathrm{AC}$ 

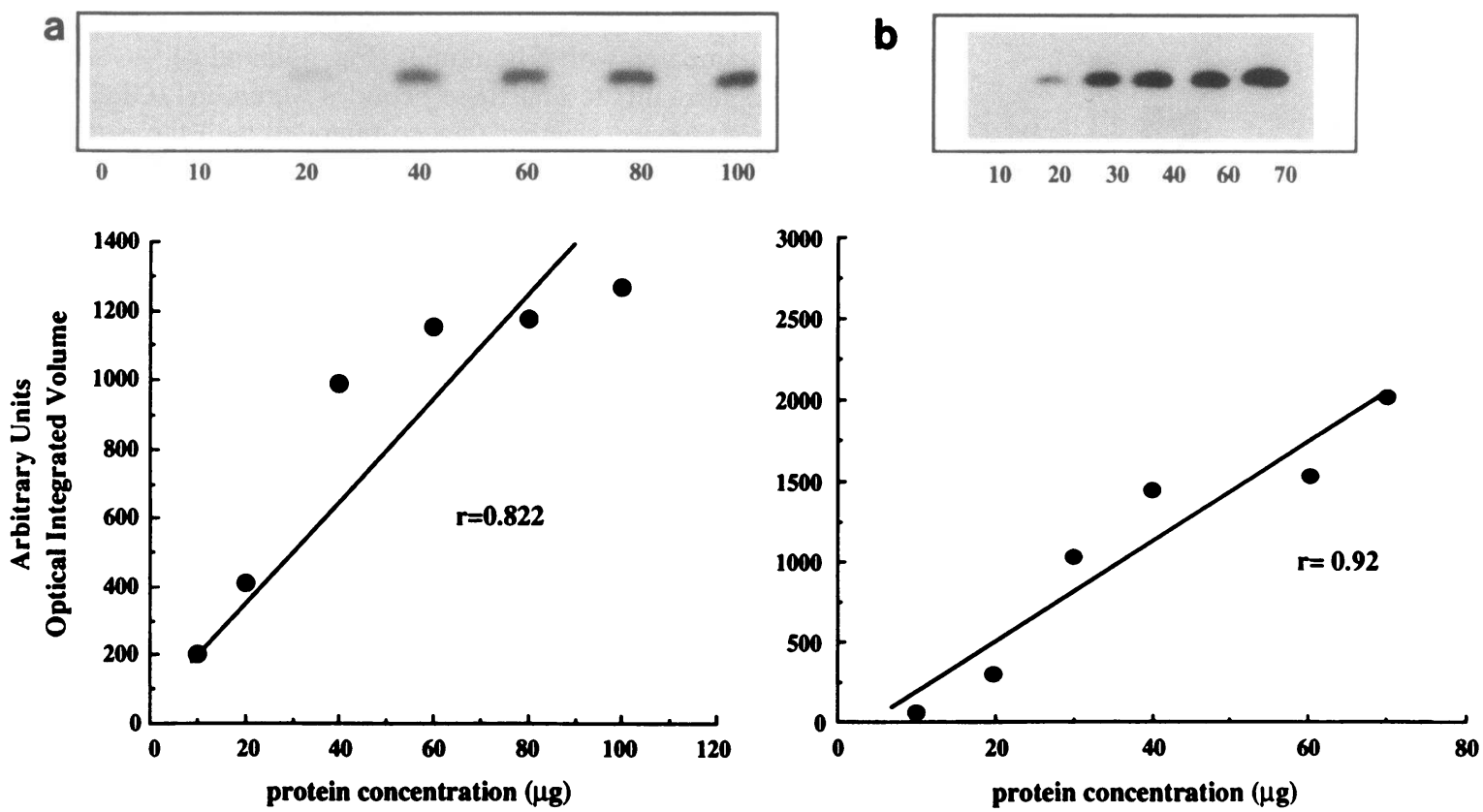

Figure 3. (a) Relationship between protein concentration and pertussis toxin-mediated ADP-ribosylation. Varying amounts of membrane protein from superior mesenteric artery were incubated with activated pertussis toxin for $90 \mathrm{~min}$ and then electrophorectically separated on SDSPAGE. Autoradiography of the $40,000 \mathrm{~mol} \mathrm{wt}$ ADP-ribosylated protein is shown above in inset. Densitometric measurements of the autoradiographic bands are plotted using arbitrary units (optical integrated volume). (b) Linear relationship between protein concentration and immunochemical detection of the Gi $\alpha 1 /$ Gi $\alpha 2$ with antiserum AS/7 and ${ }^{125}$ I-rProtein A. Increasing amounts of superior mesenteric artery membranes were electrophoretically separated on SDS-PAGE, transferred to a nitrocellulose support membrane, and processed with AS/7 antiserum and ${ }^{125} \mathrm{I}$-rProtein A. Autoradiography of the immunodetectable $40,000 \mathrm{~mol}$ wt protein is shown above in inset. Densitometric measurements of the autoradiographic bands are plotted using arbitrary units (optical integrated volume).

was significantly attenuated in PHT splanchnic and systemic arterial beds and potentiated in PHT portal vein. There is good evidence that the CAMP system mediates the vasodilatory responses to various hormones (18). We concentrated our studies on G-proteins and their activity because G-proteins play an important role in the regulation of intracellular signal trans- duction pathways, $\mathrm{AC}$ and phospholipase $\mathrm{C}$, both of which regulate vascular tone (18).

A significant decrease in the stimulatory effects of $\mathrm{Gpp}(\mathrm{NH}) \mathrm{p}$ and forskolin on AC activity in superior mesenteric artery and thoracic aorta from PHT animals was demonstrated. The results of both the cholera toxin-catalyzed ADP-ri- a Pertussis toxin-ADP-ribosylation

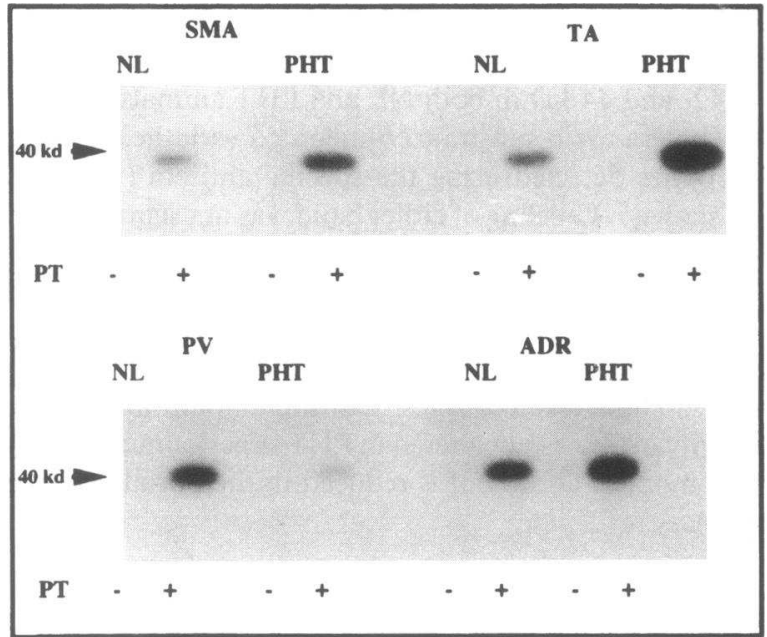

b

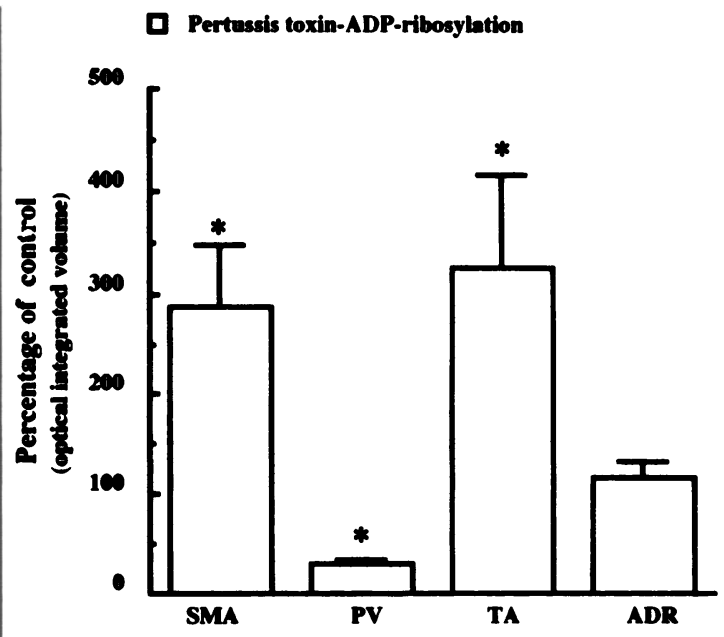

Figure 4. (a) Autoradiograph of pertussis toxin-mediated ADP-ribosylation of a 40,000-mol wt protein in normal (NL) and portal hypertensive (PHT) superior mesenteric artery, thoracic aorta, portal vein and adrenal membranes. $(b)$ Relative levels of pertussis toxin-mediated ADP-ribosylation of 40,000-mol wt protein in PHT. Relative levels were calculated as a percent of the mean optical integrated volume of detectable bands from 4 normal controls. Values represent the means \pm SEM of four separate experiments $\left({ }^{*} P<0.05\right.$ after Wilcoxon signed rank test $)$. 

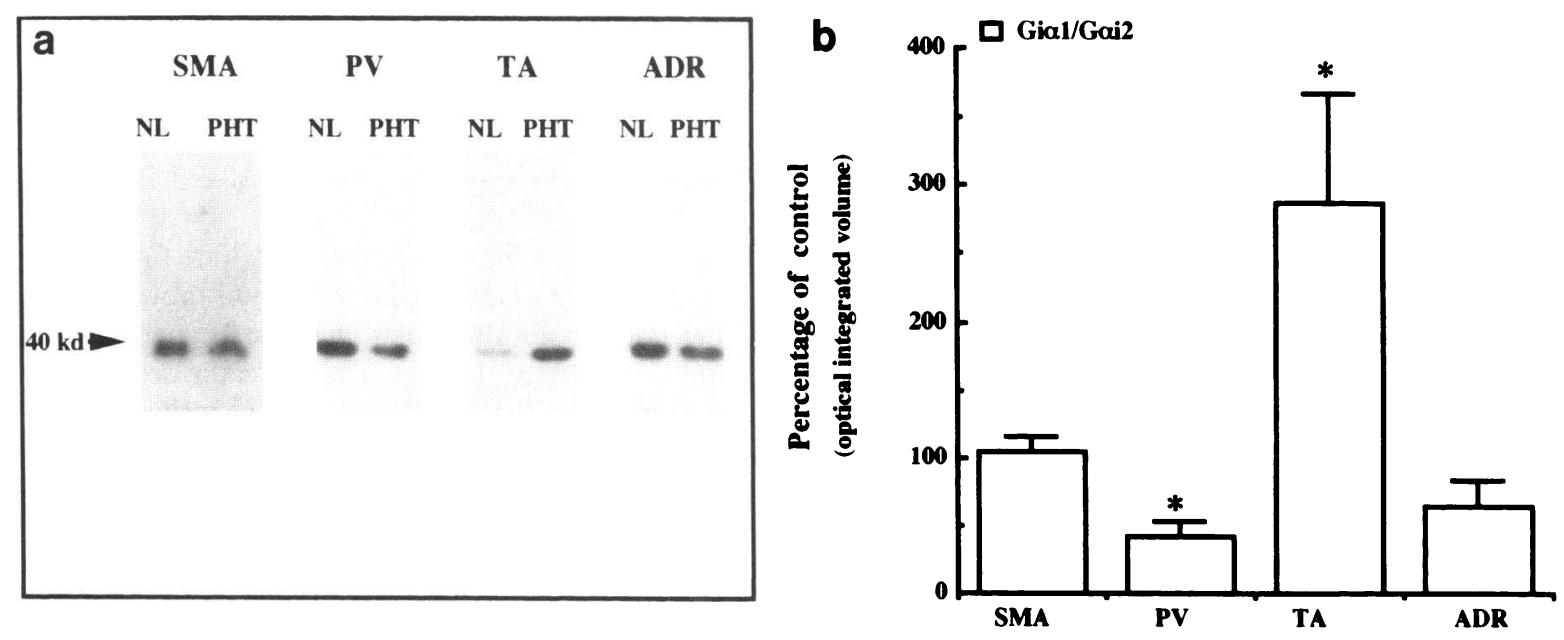

Figure 5. (a) Autoradiograph of immunodetectable Gi $\alpha 1 / \mathrm{Gi} \alpha 2$ (AS/7) protein(s) in normal (NL) and portal hypertensive (PHT) superior mesenteric artery, thoracic aorta, and portal vein. $(b)$ Relative levels of immunodetectable 40,000-mol wt (Gi $\alpha 1 /$ Gi $\alpha 2)$ protein in PHT. Relative levels were calculated as a percent of the mean optical integrated volume of detectable bands from 4 normal controls. Values represent the means \pm SEM of four separate experiments $\left({ }^{*} P<0.05\right.$ after Wilcoxon signed rank test $)$.
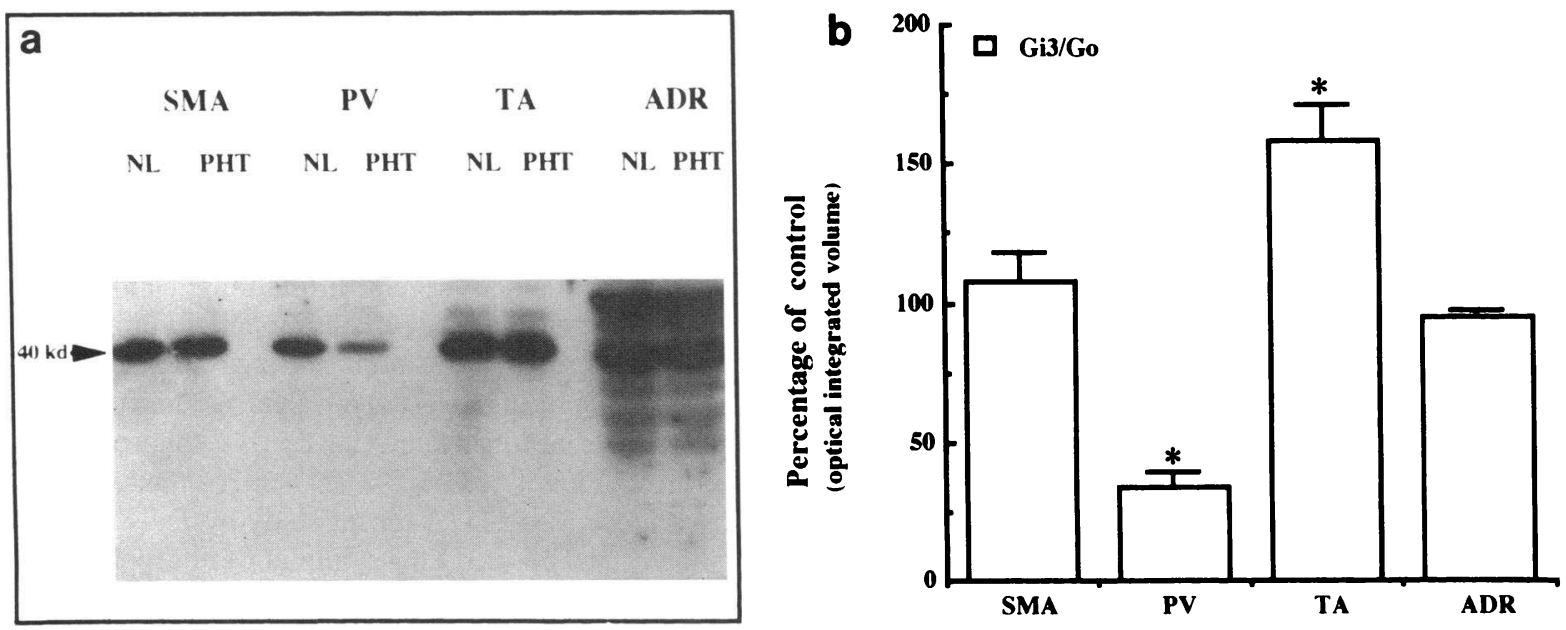

Figure 6. (a) Autoradiograph of immunodetectable Gi $3 / \mathrm{Go} \alpha(\mathrm{EC} / 2)$ protein(s) in normal (NL) and portal hypertensive (PHT) superior mesenteric artery, thoracic aorta, portal vein and adrenal membranes. (b) Relative levels of immunodetectable 40,000-mol wt (Gi $\alpha 3 / \mathrm{Go} \alpha)$ protein in PHT. Relative levels were calculated as a percent of the mean optical integrated volume of detectable bands from 4 normal controls. Values represent the means \pm SEM of four separate experiments $\left({ }^{*} P<0.05\right.$ after Wilcoxon signed rank test $)$.
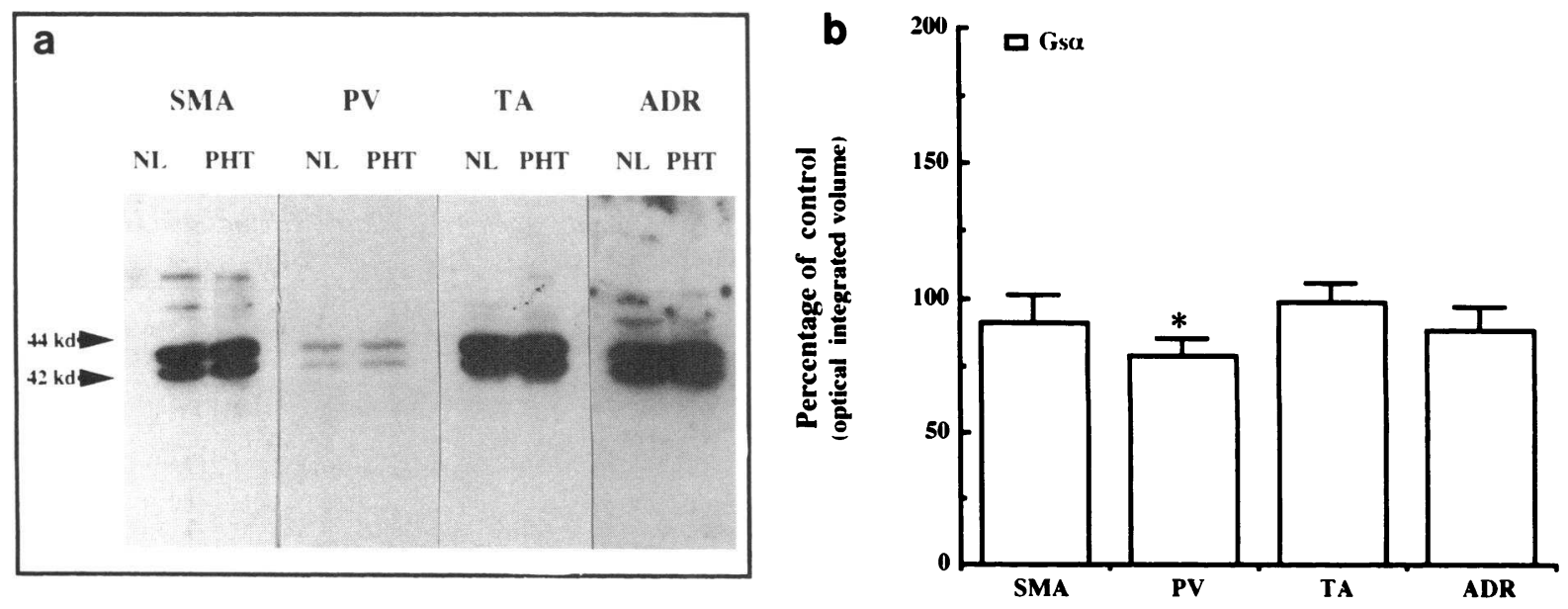

Figure 7. (a) Autoradiograph of immunodetectable Gs $\alpha$ (RM/1) proteins in normal (NL) and portal hypertensive (PHT) superior mesenteric artery, thoracic aorta, portal vein, and adrenal membranes. (b) Relative levels of immunodetectable 42,000-and 44,000-mol wt (Gs $\alpha$ ) proteins in PHT. Relative levels were calculated as a percent of the mean optical integrated volume of detectable bands from 4 normal controls. Values represent the means \pm SEM of four separate experiments $\left({ }^{*} P<0.05\right.$ after Wilcoxon signed rank test $)$. 


\section{Cholera-toxin ADP-ribosylation}
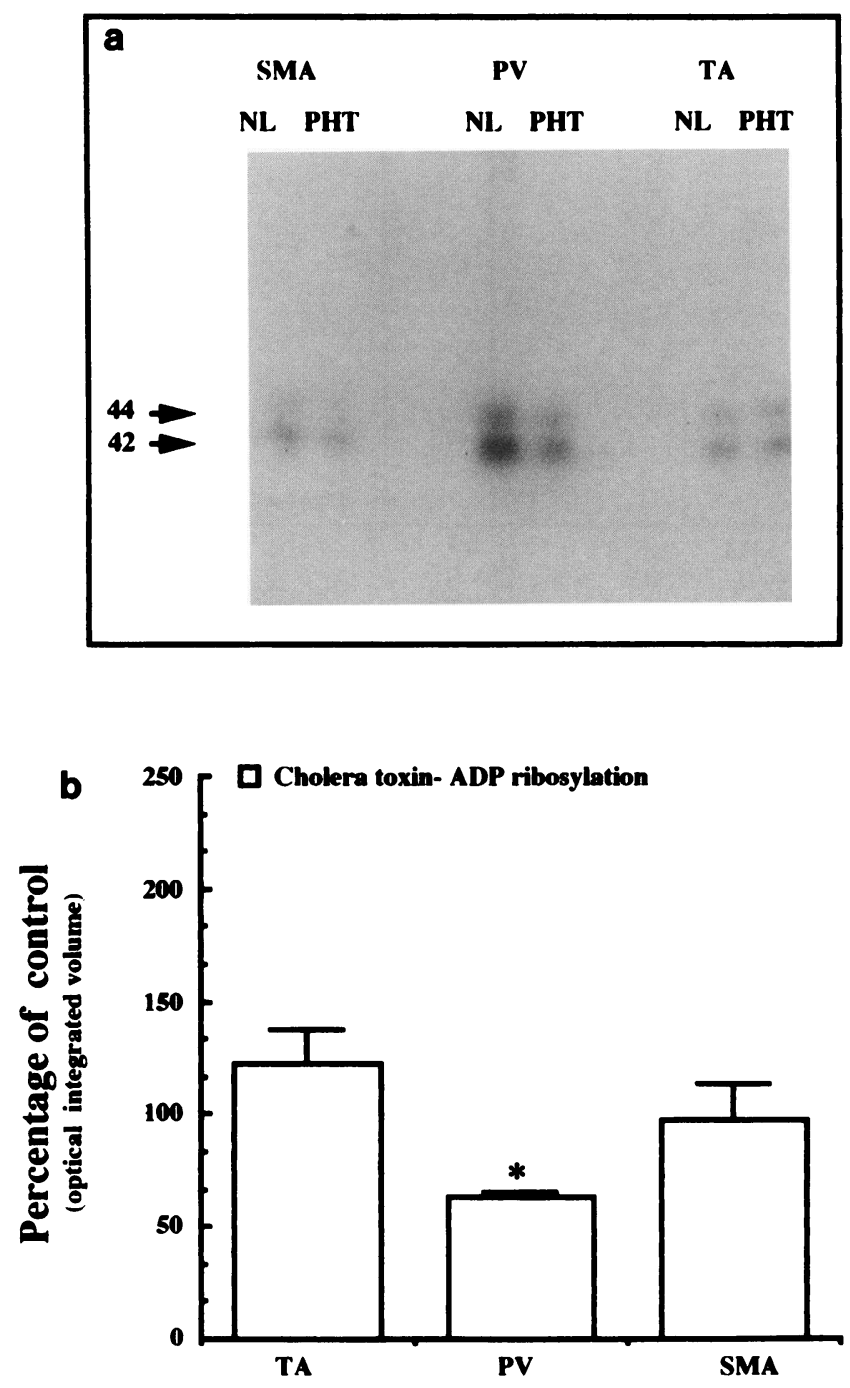

Figure 8. (a) Autoradiograph of cholera toxin-catalyzed ribosylation of 42,000- and 44,000-mol wt proteins in normal (NL) and portal hypertensive (PHT) superior mesenteric artery, thoracic aorta, and portal vein membranes. $(b)$ Relative levels of cholera toxin-catalyzed ribosylation of 42,000- and 44,000-mol wt (Gs $\alpha$ ) proteins in PHT.

Relative levels were calculated as a percent of the mean optical integrated volume of detectable bands from normal controls. Values represent the means \pm SEM of three separate experiments $\left({ }^{*} P<0.05\right.$ after Wilcoxon signed rank test).

bosylation and immunochemical detection of Gs $\alpha$ in PHT superior mesenteric artery and thoracic aorta membranes suggest that alterations in levels of this stimulatory G-protein may not be responsible for the decreased $\mathrm{Gpp}(\mathrm{NH})$ p stimulation. No difference was observed in the amount or functional activity of the Gs $\alpha$ protein in these PHT membranes.

Another explanation for the decreased sensitivity of $\mathrm{AC}$ to stimulation by forskolin in superior mesenteric artery and thoracic aorta from PHT animals may be a defective catalytic subunit of the enzyme itself or to altered expression of G-proteins, or both. Hence, the possibility of changes in the catalytic subunit of the cyclase enzyme was investigated by studying the effects of manganese ions on forskolin-stimulated AC activity in PHT. The data suggest that since the differences between
PHT and NL animals were not attenuated in the presence of manganese, the catalytic subunit of the enzyme may be impaired. It seems therefore that there is a real change in the responsiveness of AC in PHT membranes that may be accounted for by an intrinsic change in the basal activity of the enzyme.

Activation of G-proteins by $\mathrm{Gpp}(\mathrm{NH}) \mathrm{p}$ allows for the expression of both the stimulatory and inhibitory G-protein pathways, and the amount of AC stimulation is due to a net effect of both Gi $\alpha$ and Gs $\alpha$ activity $(13,23)$. Therefore, the decrease in basal AC activity and the decreased responsiveness to $\mathrm{Gpp}(\mathrm{NH}) \mathrm{p}$ in preparations derived from superior mesenteric artery and thoracic aorta of PHT animals could be due to an increase in inhibitory Gi protein activity. We have demonstrated that the levels of pertussis toxin substrate are significantly increased in particulate fractions from PHT superior mesenteric artery and thoracic aorta (Table III). In contrast the enhanced stimulation of $\mathrm{AC}$ by $\mathrm{Gpp}(\mathrm{NH}) \mathrm{p}$ and forskolin in PHT portal vein membranes was associated with a marked decrease in pertussis toxin-mediated ADP-ribosylation (70\%) of Gi $\alpha$ despite a smaller $20 \%$ reduction in Gs $\alpha$ ribosylation by cholera toxin. These changes may account for the large increases in AC activity measured within this PHT vessel. No differences were observed in the amount of pertussis toxin-catalyzed labeling of Gi $\alpha$ protein in adrenal membranes prepared from PHT animals.

Unfortunately, evaluating the functional activity of Gi $\alpha$ proteins utilizing pertussis toxin-mediated ADP-ribosylation of Gi-protein substrates has several limitations. Namely $(a)$ ADP-ribosylation measures only a subunit activity of a given G-protein (13), (b) ADP-ribosylation is strongly dependent on the substrate quality of the Gi $\alpha,(c)$ covalent modifications of the acceptor site for pertussis toxin $(24,25),(d)$ phospholipid membrane environment of $\operatorname{Gi} \alpha(13,24)$ and $(e)$ endogenous ADP-ribosyltransferase (26). A recent study by Taussig et al. (23) has shown that purified Gi $\alpha$ subunits were capable of a concentration-dependent inhibition of $\mathrm{AC}$ and that myristoylation of $\mathrm{Gi} \alpha$ proteins was necessary for this inhibition. However, the sensitivity of the electrophoretic procedure adopted in the present study does not detect minor modifications in the peptide structure. Recent studies also suggest that the free $\beta$-subunit of G-proteins rather than Gi $\alpha$ mediates the inhibition of $\mathrm{AC}(13,27)$. Hence, the activity of the $\beta$-subunit may be as important in the overall responsiveness of the AC system as the activity of $\mathrm{Gi} \alpha(13)$. These data allow for the possibility

Table III. Summary of Adenylyl Cyclase Activities and G-Protein Changes in PHT Vessels

\begin{tabular}{|c|c|c|c|c|c|}
\hline & \multirow{2}{*}{ 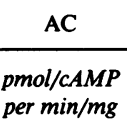 } & \multicolumn{2}{|c|}{ Gs $\alpha$} & \multicolumn{2}{|c|}{ Gi $\alpha$} \\
\hline & & $C T$ & $A b$ & $P T$ & $A b$ \\
\hline SMA & 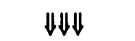 & $\Rightarrow \Leftarrow$ & $\Rightarrow \Leftarrow$ & $\mathbb{\Uparrow} \Uparrow \Uparrow \Uparrow$ & $\Rightarrow \Leftarrow$ \\
\hline PV & $\Uparrow \Uparrow \Uparrow$ & $\Downarrow$ & $\Downarrow$ & 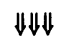 & 丩丩 \\
\hline TA & ฟ丩ฟ & $\Rightarrow \Leftarrow$ & $\Rightarrow \Leftarrow$ & $\Uparrow \Uparrow \Uparrow$ & $\Uparrow \Uparrow \Uparrow$ \\
\hline ADR & $\Rightarrow \Leftarrow$ & $\Rightarrow \Leftarrow$ & $\Rightarrow \Leftarrow$ & $\Rightarrow \Leftarrow$ & $\Rightarrow \Leftarrow$ \\
\hline
\end{tabular}

AC, adenylyl cyclase; ADR, Adrenals; CT, cholera-toxin catalyzed ADP-ribosylation; PT, pertussis-toxin catalyzed ADP-ribosylation; PV, portal vein; SMA, superior mesenteric artery; TA, Thoracic aorta. 
of endogenous covalent modifications (e.g., isoprenylation and myristoylation ) of Gi $\alpha$ which might affect exogenous pertussis toxin-induced $\left[{ }^{32} \mathrm{P}\right] \mathrm{ADP}$ labeling or alternatively the percentage of $\mathrm{Gi} \alpha$ proteins that are capable of inhibiting the AC enzyme.

Since altered pertussis toxin radiolabeling in membranes from PHT vessels may not reflect the absolute levels of the Gi $\alpha$ proteins, we determined the amount of expressed $\mathrm{Gi} \alpha$ protein using specific antisera raised against Gi $\alpha 1 / \mathrm{Gi} \alpha 2$ and $\mathrm{Gi} \alpha 3 /$ Go $\alpha$. We demonstrated enhanced levels of Gi $\alpha 1 / \mathrm{Gi} \alpha 2$ and Gi $\alpha 3 /$ Go $\alpha$ in PHT thoracic aorta preparations and reduced levels of these peptides in portal vein from PHT animals. However, the levels of $\mathrm{Gi} \alpha$ peptides in the superior mesenteric artery and adrenals of PHT were unaltered (Table III). In the thoracic aorta and portal vein, the close correlation between altered functional activity of $\mathrm{Gi} \alpha$ proteins in PHT animals, as determined by $(a)$ pertussis toxin-catalyzed ADP-ribosylation and $(b)$ the amounts of immunoreactive Gi $\alpha$ in the same preparations suggests that these changes may be responsible for the differential responsiveness of PHT membranes to stimulation of AC by guanine nucleotides and forskolin (Table III). However, this is not the case with respect to the PHT superior mesenteric artery membranes, where the increased functional activity of $\mathrm{Gi} \alpha$ is not associated with changes in the levels of immunodetectable Gi $\alpha$ (Table III).

The etiology of the discordance between immunodetectable levels of Gi $\alpha$-proteins in the superior mesenteric artery of PHT and measurements of AC activity and levels of pertussis toxin substrate are not obvious. A covalent modification could augment Gi $\alpha$ function in PHT, or alternatively, the modification might normally reduce Gi $\alpha$ function in NL animals. In any case, a covalent modification could allow for a more complete ADP-ribosylation by pertussis toxin in PHT membranes. Several covalent modifications of G-proteins that alter Gi $\alpha$ bioactivity have been described $(23,28,29)$. The reason for the selective changes within these blood vessels may also be related to the enhanced level of vasoactive substances locally released within the mesentery after acute portal vein ligation. We and others have shown significant increases in the local production of prostacyclin, nitric oxide, and glucagon, which may acutely modulate the signal transducing pathways in PHT superior mesenteric artery but not systemically $(2,4,7,9,10,30)$. For example, previous studies have demonstrated portal venous prostacyclin activity exceeded peripheral venous activity twoto threefold in PHT (30). Moreover previous studies have shown that increased splanchnic and portal venous vasodilator substances (i.e., glucagon, prostacyclin, and bile acids) and reduced vascular responsiveness of the superior mesenteric artery to exogenous vasoconstrictors (i.e., angiotensin-II, norepinephrine, and vasopressin) both contribute to the intestinal vasodilation associated with chronic PHT, independent of variations in systemic cardiovascular homeostasis (11). It is possible therefore that changes in the responsiveness of vasoconstrictor hormones occur selectively in some vascular beds and are absent in others due to regional elevated levels of endogenous vasodilators and their subsequent modification of the signalling transducing pathways within a specific vascular bed.

Up-regulation of $\mathrm{Gi} / \mathrm{Go}$ proteins may play a central role in the long-term adaptation of the arterial systemic and splanchnic vascular beds to chronic activation of $\mathrm{AC}$ by endogenous vasodilators (glucagon and prostacyclin). Accordingly, chronic stimulation of the $\beta$-adrenoreceptor AC pathway re- sulted in up-regulation of $\mathrm{Gi} \alpha$ protein levels (31). Chronic pathological states, such as human heart failure, are associated with increased functional activity of $\mathrm{Gi} \alpha$ (13). It may be that the up-regulation of $\mathrm{Gi} \alpha / \mathrm{Go} \alpha$ protein levels and pertussis toxin-sensitive G-proteins in the superior mesenteric artery and thoracic aorta from PHT animals are chronic regulatory events initiated by high circulating levels of endogenous vasodilators. Increases in Gi $\alpha$ proteins may not only contribute to the desensitization of stimulatory AC pathways (32), but also may lead to sensitization (hyperactivity) of inhibitory adenylyl cyclase and phospholipase $\mathrm{C}$ pathways $(31,32)$.

The results of the present study have been obtained in a model of prehepatic PHT. The finding that different humoral factors are important in the pathogenesis of PHT is now well established and increased levels of endogenous vasodilators ( $\mathrm{PGI}_{2}$ and glucagon) have been reported in prehepatic and cirrhotic models of PHT $(4,5,7)$. Previous studies have suggested isolated superior mesenteric vein, and portal vein from PHT rats, were less sensitive to the vasoconstrictive effects of norepinephrine (33-35). Although the specific vascular receptors were not determined in this present study, it is conceivable that the dramatic decrease in the amount and functional activity of $\mathrm{Gi} \alpha$ in portal vein of PHT, despite a smaller reduction in the amount and functional activity of $\mathrm{Gs} \alpha$, may modulate signal transduction to several intracellular pathways, leading to an overall reduced splanchnic sensitivity to vasoconstrictive stimulation $(34,35)$. Alternatively, these changes in G-protein levels and function may be associated with the marked vascular smooth muscle hypertrophy after partial ligation of the portal vein in this model of prehepatic PHT (35). Various studies of the portal vein in experimental PHT have revealed a dramatic structural response of the smooth muscle and profound functional adjustments with respect to contractile force and responsiveness to catecholamines (35).

In summary, we have demonstrated that the expression of Gi $\alpha$ regulatory proteins are altered in PHT. Chronic liver disease has been known for many years to be associated with changes in the splanchnic and systemic circulation (1). Similar changes have been reported in experimental prehepatic models of PHT (1). The current studies define for the first time altered levels of guanine-nucleotide regulatory proteins in the vasculature of PHT animals. Further studies are necessary to determine if these changes in G-protein function are part of, the cause of, or a consequence of the hyperdynamic vasculopathy of PHT.

\section{Acknowledgments}

We thank Carol St. Clair for her excellent technical assistance and Dr. Antonio DeMaio for his review of the manuscript and helpful suggestions.

This work was supported in part by grant 92009340 from the American Heart Association and National Institutes of Health grant R29HL39683.

\section{References}

1. Reichen, J. 1990. Liver function and pharmacological considerations in the pathogenesis and treatment of portal hypertension. Hepatology. 11:1066-1078.

2. Vorobioff, J., J. E. Bredfeldt, and R. J. Groszmann. 1983. Hyperdynamic circulation in portal hypertensive rat model: a primary factor for maintenance of chronic portal hypertension. Am. J. Physiol. 244:G52-G57.

3. Sitzmann, J. V., S. S. Li, and P. W. Lin. 1989. Prostacyclin mediates splanchnic vascular response to norepinephrine in portal hypertension. J. Surg. Res. 47:208-211. 
4. Sitzmann, J. V., G. B. Bulkley, M. Mitchell, and K. Campbell. 1988. Role of prostacyclin in the splanchnic hyperemia contributing to portal hypertension. Ann. Surg. 209:322-327.

5. Wu, Y., S. S. Li, K. A. Campbell, and J. V. Sitzmann. 1991. Modulation of splanchnic vascular sensitivity to angiotensin II. Surgery. 110:162-168.

6. Kiel, J. W., V. Pitts, J. N. Benoit, D. N. Granger, and A. P. Shepherd. 1985 Reduced vascular sensitivity to norepinephrine in portal hypertensive rats. Am.J. Physiol. 248:G192-G195.

7. Benoit, J. N., B. Zimmerman, A. J. Premem, V. L. W. Go, and D. N. Granger. 1986. Role of glucagon in splanchnic hyperemia of chronic portal hypertension. Am. J. Physiol. 251:G674-G677.

8. Ballet, F. 1990. Hepatic circulation: potential for therapeutic intervention Pharmacol. Ther. 47:281-328.

9. Pizcuetta, P., J. M. Pique, J. Bosch, B. J. R. Whittle, and S. Moncada. 1992. Effects of inhibiting nitric oxide biosynthesis on the systemic and splanchnic circulation changes of rats with portal hypertension. Br. J. Pharmacol. 105:184190.

10. Cahill, P. A., Y.-P. Wu, and J. V. Sitzmann. 1993. Nitric oxide synthase activity in portal hypertension. Hepatology. 18:141A.

11. Joh, T., D. N. Granger, and J. N. Benoit. 1993. Endogenous vasoconstrictor tone in intestine of normal and portal hypertensive rats. Am. J. Physiol. 264:H171-H177.

12. Willet, I. R., M. Esler, G. Jennings, and F. J. Dudley. 1986. Sympathetic tone modulates portal venous pressure in alcoholic cirrhosis. Lancet. ii:939-943.

13. Levitzki, A., and A. Bar-Sinai. 1991. The regulation of adenylyl cyclase by receptor G proteins. Pharmacol. Ther. 50:271-283.

14. Gerbes, A. L., J. Remien, D. Juengst, T. Sauerbruch, and G. Paumgartner 1986. Evidence for down-regulation of beta-2-adrenoceptors in cirrhotic patients with severe ascites. Lancet. i:1409-1411.

15. Ramond, M. J., E. Comoy, and D. Lebrec. 1986. Alterations in isoprenaline sensitivity in patients with cirrhosis: evidence of abnormality of the sympathetic nervous activity. Br. J. Clin. Pharmacol. 21:191-196.

16. Kaumann, A. J., and R. J. Groszmann. 1989. Catecholamines relax portal and mesenteric veins from normal and portal hypertensive rats. Am. J. Physiol. 257:20:G977-G981.

17. Villamediana, L. M., G. Dieguez, J. C. Santos, A. L. Gracia-Villalon, C Caramelo, and J. M. Lopez-Novoa. 1988. Vascular reactivity to norepinephrine in rats with cirrhosis of the liver. Can. J. Physiol. Pharmacol. 66:567-572.

18. Brodde, O. E., and M. C. Michel. 1992. Adrenergic receptors and their signal transduction mechanisms in hypertension. J. Hypertension. 10:S133S145.

19. Bradford, M. M. 1976. A rapid and sensitive method for quantification of microgram quantities of protein utilizing the principle of protein dye binding. Ann. Biochem. 72:248-254.

20. Feldman, A. M., A. E. Cates, W. B. Veazey, R. E. Hershberger, M. R.
Bristow, K. I. Baughman, W. A. Baumgartner, and C. VanDop. 1988. Increase of the 40,000 -mol wt pertussis toxin substrate (G-protein) in the failing human heart. J. Clin. Invest. 82:189-197.

21. Laemmli, U. K. 1970. Cleavage of structural proteins during the assembly of the head of bacteriophage T. Nature (Lond.). 227:680-685.

22. Cech, S. Y., W. C. Broaddus, and M. E. Maguire. 1980. Adenylate cyclase: the role of magnesium and other divalent cations. Mol. Cell. Biochem. 33:67-92.

23. Taussig, R., A. J. Iniguez-Lluhi, and A. G. Gilman. 1993. Inhibition of adenylyl cyclase by Gi $\alpha$. Science (Wash. DC). 261:218-221.

24. Milligan, G. 1988. Techniques used in the identification and analysis of function of pertussis toxin-sensitive guanine nucleotide regulatory proteins. Bio chem. J. 255:1-13.

25. Glomest, J. A., M. H. Gelb, and C. C. Farnworth. 1990. Phenyl proteins in eukaryotic cells: a new type of membrane anchor. Trends Biochem. Sci. 15:139_ 142.

26. Tanuma, S., K. Kawashkma, and H. Endo. 1988. Eukaryotic mono-ADP. ribosyltransferase that ADP-ribosylates GTP-binding regulatory Gi $\alpha$ protein. $J$. Biol. Chem. 263:5485-5489.

27. Enomoto, K., and T. Asakawa. 1986. Inhibition of catalytic unit of adenylyl cyclase and activation of GTPase of Ni protein by $\beta$-subunits of GTP-binding proteins. FEBS Lett. 202:63-68.

28. Feldman, A. M. 1991. Experimental issues in assessment of $G$ protein function in cardiac disease. Circulation. 84:1852-1861.

29. Bohm, M., P. Gierschik, A. Knorr, K. Larisch, K. Weismann, and E. Erdmann. 1992. Role of altered G-protein expression in the regulation of myocardial adenylyl cyclase activity and force of contraction in spontaneous hypertensive cardiomyopathy in rats. J. Hypertens. 10:1115-1128.

30. Hashizume, M., K. Inokuchi, and K. Tanaka. 1985. The role of prostacyclin in patients with portal hypertension. Liver. 5:89-93.

31. Eschenahagen, T., U. Mende, M. Diederich, M. Nose, W. Schmitz, H. Scholz, S. C. Esch, A. Warnholtz, and H. Schaffer. 1992. Long-term $\beta$-adrenoceptor-mediated up-regulation of $\mathrm{Gi} \alpha$ proteins, $\mathrm{Gi} \alpha$ mRNA levels and pertussis toxin-sensitive guanine nucleotide-binding proteins in rat heart. Mol. Pharmacol. 42:773-783.

32. Milligan, G., and G. Green. 1991. Agonist control of G-protein levels. Trends Pharmacol. Sci. 12:207-209.

33. Cummings, S. A., R. J. Groszmann, and A. K. Kaumann. 1986. Hypersensitivity of mesenteric veins to 5-hydroxytryptamine- and ketanserin-induced reduction of portal pressure in portal hypertensive rats. Br. J. Pharmacol. 89:501513.

34. Groszmann, R. J., and A. J. Kaumann. 1983. Loss of response to alphaadrenoceptor stimulation in the superior mesenteric vein of rats with chronic portal hypertension. Naunyn-Schmiedeberg's Arch. Pharmakol. 324:R12.

35. Johansson, B. 1976. Structural and functional changes in rat portal veins after experimental portal hypertension. Acta Physiol. Scand. 98:381-383. 